\title{
MINDFULNESS DENGAN PERILAKU PERAN SAKIT PADA PASIEN PASCA STROKE
}

\author{
Andi Dian Diarfah ${ }^{1}$, Andi Weri Sompa ${ }^{2}$ \\ ${ }^{1}$ Universitas Islam Negeri Alauddin Makassar \\ e-mail : andidian@gmail.com \\ ${ }^{2}$ Universitas Muhammadiyah Makassar \\ e-mail : awerisompa@gmail.com
}

\begin{abstract}
Abstrak
Stroke merupakan penyebab umum dari kecacatan dan memiliki dampak besar pada kehidupan individu. Pemulihan stroke sangat individual dan memerlukan proses yang panjang. Dukugan keluarga tidak cukup memberikan pengaruh terhadap kesembuhan penderita pasca stroke, adanya kesadaran dari penderita pasca stroke sendiri untuk sembuh juga diperlukan. Tujuan dari penelitian ini untuk mengetahui pengaruh mindfulness terhadap sick role behavior pada penderita pasca stroke. Subjek dalam penelitian ini sebanyak 110 orang dengan karakteristik berusia 30-65 tahun. Instrument yang digunakan dalam penelitian adalah The Applied Mindfulness Process Scale (AMPS) dam Barcylas Sick Role Process Inventory (BSRPI). Analisis yang digunakan yaitu dengan teknik Mediated Multiple Regression. Hasil penelitian menunjukkan bahwa ada hubungan antara mindfulness dengan perilaku peran sakit $(\beta=0.51, \mathrm{p}<0.05)$.
\end{abstract}

Kata Kunci: Mindfulness, sick role behavior, stroke

\begin{abstract}
Stroke is a common cause of disability and has a large impact on an individual's life. Stroke recovery is very individual and requires a long process. Family support is not enough to give effect to the recovery of post-stroke sufferers, the mindfulness of post-stroke sufferers themselves to recover is also needed. The purpose was determined the relationship between mindfulness with sick role behavior in post-stroke patients with. The subjects were 110 people with characteristics aged 30-65 years. The instruments of this study were the Applied Mindfulness Process Scale (AMPS) and Barcylas Sick Role Process Inventory (BSRPI). The technique of Mediated Multiple Regression was the data analysis. The results showed there was a correlation between mindfulness and sick role behavior $(\beta=0.51, \mathrm{p}<0.05)$.
\end{abstract}

Keywords: Mindfulness, Sick Role Behavior, Stroke

\section{PENDAHULUAN}

Penderita stroke mengalami banyak penurunan perubahan setelah mengalami serangan stroke. Perubahan emosional adalah hal yang mungkin terjadi setelah mengalami stroke sehingga dapat memunculkan gejala psikologis yang negatif. Terjadinya keadaan psikologis yang negatif pada panderita stroke disebabkan karena adanya perubahan pada activities of daily living, misalnya dalam urusan rumah tangga, pemenuhan kebutuhan nutrisi, pemenuhan kebutuhan mobilisasi, dan juga kelelahan (National Stroke Association, 2016)..
Pengalaman negatif yang terjadi pada seseorang dapat menjadi tekanan yang menyiksa bagi sebagian individu. Pengalaman negatif tersebut dapat menyebabkan mereka bereaksi secara tidak efektif seperti menyalahkan diri sendiri, marah kecewa, merasa sendirian, merasa tidak berdaya, putus asa, bahkan gangguan mental lainnya (Chriki, Bullain, \& Stren, 2006; Sarah \& Clark, 2011). Profesional kesehatan perlu hati-hati menafsirkan pengalaman dan persepsi pasien stroke dalam rangka untuk mendapatkan pemahaman yang lebih baik di mana mereka berada dalam pemulihan pasca- 
stroke. Hal ini akan memastikan tingkatkan perawatan untuk mempromosikan pemulihan setelah stroke (Ahuja et al, 2012).

Terdapat banyak faktor yang berpengaruh terhadap kesembuhan pasien pasca stroke baik faktor eksternal dan internal (National Stroke Association, 2016). Dukungan sosial dari keluarga sebagai faktor eksternal dianggap sebagai faktor penting dalam proses kesembuhan pasien. Kenyataannya beberapa pasien yang memiliki dukungan sosial yang tinggi dari keluarga, tidak menunjukkan adanya kesembuhan yang signifikan. Penelitian menunjukkan bahwa keluarga tidak memiliki waktu yang cukup untuk menghadapi proses penyembuhan pasien stroke yang panjang (Lutz, 2011). Hal tersebut berarti faktor eksternal kurang memberikan pengaruh terhadap kesembuhan pasien pasca stroke.

Adapun faktor internal bersumber dari pasien tersebut yaitu keinginan untuk berobat dan menjalani perawatan. Perawatan yang tepat untuk memastikan kualitas penyembuhan yang konsisten tidak terlepas dari pengetahuan tentang stroke itu sendiri (Eriksson, Milberg, Hjelm, \& Friedrichsen, 2016). Pengetahuan tersebut dapat membantu mereka untuk bisa lebih menjaga diri. Faktanya lamanya waktu yang dibutuhkan untuk proses penyembuhan stroke, membuat beberapa pasien stroke lambat laun kurang peduli dengan kesembuhan mereka (Mant, Winner, Roche, \& Wade, 2005). Oleh karena itu, pasien stroke memerlukan kesadaran dari dirinya sendiri dalam melakukan proses penyembuhannya (Leung \& Liu, 2011).

Banyak tradisi filsafat, spiritual, dan psikologis menekankan pentingnya kualitas kesadaran untuk pemeliharaan dan peningkatan kesejahteraan. Hubungan antara kualitas kesadaran dan kesejahteraan masih mulai mendapatkan perhatian empiris. Salah satu atribut kesadaran yang telah banyak dibahas dalam kaitannya dengan kesejahteraan adalah mindfulness.

Mindfulness adalah hasil (kesadaran mindful) dan proses dari (praktik mindful): (1) kesadaran mindful: hadirnya kesadaran, yang bermanifestasi sebagai kebebasan pikiran (misalnya, kebebasan dari berpikir secara spontan), dan (2) latihan mindful: latihan yang sistematis yang dengan sengaja menghadirkan keterbukaan, kepedulian, dan cara cerdas untuk apapun yang terjadi saat ini, yang melibatkan pengetahuan dan membentuk pikiran (Shapiro \& Carlson, 2009).

Sebelum seseorang bebas dari penyakit dan peran sakit (sick role), mereka harus mengetahui gejala-gejala dan cara menangani penyakit tersebut. Perhatian utama dari perilaku peran sakit yaitu bagaimana peran sakit dapat mencegah individu untuk melakukan hal-hal yang merugikan terkait sakitnya. Adapun konsep perilaku peran sakit dimulai dari gejala sakit yang dirasakan, dievaluasi kemudian ditindaklanjuti dengan melakukan tindakan penyembuhan (Barclay, 2012). Kesadaran memungkinkan seseorang untuk melihat apa yang terjadi dalam kehidupannya, dapat mengamati pikiran, perasaan dan sensasi yang timbul dalam dirinya. Mindfulness merupakan bentuk dasar dari kesadaran untuk adanya perubahan yang diperlukan dalam penyembuhan (Ruff \& Mackenzie, 2009).

Pasien stroke memiliki gangguan emosional yang merupakan reaksi normal atas tantangan, ketakutan, dan rasa frustrasi pasien dalam menghadapi disabilitasnya (National-StrokeAssociation, 2012). Emosi tersebut berhubungan dengan pikiran, persepsi dan dapat mengubah diri menjadi pribadi yang kaku. Mindfulness mendorong untuk mengeksplor emosi-emosi negatif tersebut sehingga terbentuk pikiran yang sehat dan mengarah ke perilaku peran sakit yang positif (Maine, McGilley, \& Bunnell, 2010). 
Tujuan pelaksanaan mindfulness adalah untuk mengambil tanggung jawab yang lebih besar dalam pilihan hidup seseorang. Dengan demikian, mindfulness dapat dipromosikan menjadi obat yang lebih partisipatif dengan melibatkan dan memperkuat sumber daya internal dari individu untuk mengoptimalkan kesehatan baik pada pencegahan maupun proses penyembuhan penyakit (Ludwig \& KabatZinn, 2008). Mindfulness mengajarkan seseorang untuk menerima keadaan sehingga melakukan perilaku peran sakit, bukan untuk menghindar dan melakukan hal yang dapat merusak diri sendiri (Greeson, 2009).

Oleh karena itu, tujuan dalam penelitian ini adalah untuk mengetahui bagaimana hubungan mindfulness dengan perilaku peran sakit pada penderita pasca stroke. Manfaat dari penelitian adalah untuk memberikan sumbangan teoritis dan praktis. Secara teoritis, penelitian ini digunakan sebagai suatu sumbangan pengetahuan dalam disiplin ilmu kesehatan.

\section{METODE}

Populasi subjek dari penelitian ini adalah pasien pasca stroke minimal 3 bulan, berusia mulai 30-65 tahun, masih memerlukan bantuan orang lain untuk melakukan aktifitas dan mampu berkomunikasi. Jumlah subjek dalam penelitian ini adalah 110 orang, 52 orang laki-laki (47\%) dan 58 orang perempuan (53\%). Teknik sampling dalam penelitian ini yaitu purposive sampling karena karakteristik subjeknya telah ditentukan sebelumnya berdasarkan ciri dan sifat populasinya (Winarsunu, 2006). Usia subjek penelitian yaitu berkisar 30-65 tahun. Untuk lebih jelasnya dapat dilihat pada tabel 1 berikut.

Terdapat dua variabel yang akan diteliti, yaitu mindfulness dan sick role behavior. Mindfulness diukur dengan The Applied Mindfulness Process Scale (AMPS). AMPS digunakan untuk mengukur seberapa besar proses mindfulness seseorang ketika menghadapi tantangan dalam kehidupan sehari-hari. Pengembangan dan validasi dari AMPS menghasilkan 15 item yang mewakili tiga domain yang diterapkan dari proses kesadaran yaitu: (a) decentering, (b) regulasi emosional positif, dan (c) regulasi emosional negatif (Garland, 2007). Berdasarkan hasil tryout, skala ini memperoleh indeks reliabilitas dalam $(\alpha$ Cronbach) 0.83 dan tersisa 11 aitem yang valid. Pilihan jawaban setiap aitem adalah Tidak Pernah, Jarang, Terkadang, Sering dan Hampir Sering. Skor aitem untuk pilihan jawaban Tidak Pernah $=0$, Jarang $=1$, Terkadang $=2$, Sering $=3$ dan Hampir Sering $=4$. Salah satu contoh skala APMS yaitu : Merilekskan tubuh saya ketika saya merasa tegang.

Perilaku peran sakit diukur dengan Barcylas Sick Role Process Inventory (BSRPI). Sebelumnya BSRPI digunakan untuk meneliti subjek yang memiliki kerusakan otak. Oleh karena itu, BSRPI ini akan diadaptasi sesuai dengan subjek yang diteliti yaitu penderita stroke. BSRPI terdiri dari dua bagian dan masing-masing bagian terdapat 12 aitem dengan pilihan jawaban Sangat Tidak Setuju, Tidak Setuju, Setuju, dan Sangat Tidak Setuju. Bagian pertama fokus pada keyakinan dan perasaan yang dimiliki di awal proses penyembuhan. Bagian kedua fokus pada keyakinan dan perasaan sekarang (Barclay, 2012). Setelah dilakukan tryout, skala ini memiliki reliabilitas ( $\alpha$ Cronbach) 0.88 dan tersisa 18 aitem. Skor aitem untuk pilihan jawaban Sangat Tidak Setuju $=1$, Tidak Setuju $=2$, Setuju $=3$ dan Sangat Setuju $=4$. Salah satu contoh aitem dari BSRPI ini yaitu: Ketika saya pertama kali mulai proses penyembuhan, saya memiliki hak untuk dibebaskan dari semua tanggung jawab sehari-hari.

\section{HASIL DAN PEMBAHASAN}

Setelah dilakukan pengambilan data sebanyak 110 orang, 52 orang laki-laki 
(47\%) dan 58 orang perempuan (53\%).

Untuk lebih jelasnya dapat dilihat pada

tabel 1 berikut.

Tabel 1. Deskripsi subjek penelitian $(\mathrm{N}=110)$

\begin{tabular}{|c|c|c|}
\hline Karakteristik & $\mathbf{F}$ & Persentase (\%) \\
\hline \multicolumn{3}{|l|}{ Jenis kelamin } \\
\hline Laki-laki & 52 & $47 \%$ \\
\hline Perempuan & 58 & $53 \%$ \\
\hline \multicolumn{3}{|l|}{ Usia } \\
\hline 30-40 tahun & 10 & $9 \%$ \\
\hline $41-50$ tahun & 23 & $21 \%$ \\
\hline 51-60 tahun & 60 & $55 \%$ \\
\hline $61-70$ tahun & 17 & $15 \%$ \\
\hline \multicolumn{3}{|l|}{ Lama sakit } \\
\hline$\leq 1$ tahun & 62 & $56 \%$ \\
\hline$>1$ tahun & 48 & $44 \%$ \\
\hline
\end{tabular}

Hasil deskripsi variabel dengan menggunakan program SPSS terhadap variabel mindfulness, dan perilaku peran sakit ditunjukkan dengan nilai rata-rata atau mean dan standar deviasi. Variabel mindfulness sebagai variabel bebas (X) memiliki nilai rata-rata $(\mathrm{M}=1.88$ dan $\mathrm{SD}$ $=0.33)$. Variabel perilaku peran sakit sebagai variabel terikat $(\mathrm{Y})$ memiliki nilai rata-rata $(\mathrm{M}=3.39$ dan $\mathrm{SD}=0.34)$. Deskripsi hasil kedua variabel dapat dilihat pada tabel 2 berikut.

Tabel 2. Mean, standar deviasi, dan hubungan antar variabel

\begin{tabular}{llllll}
\hline & Mean & SD & $\mathbf{1}$ & $\mathbf{2}$ & $\mathbf{3}$ \\
\hline 1. Mindfulness & 1.88 & 0.33 & 1 & $-0.279^{* *}$ & $0.581^{* *}$ \\
\hline 2. Perceived stress & 2.31 & 0.28 & & 1 & $-0.442^{* *}$ \\
\hline 3. Perilaku peran sakit & 3.39 & 0.34 & & 1 \\
\hline Keterangan: $\mathrm{N}=110 ; * * \mathrm{p}<0.01$ & & & & \\
\hline
\end{tabular}

Berikut hasil pengujian hipotesis antara mindfulness terhadap perilaku peran sakit.

Tabel 3. Uji Hipotesis

\begin{tabular}{ccc}
\hline Hubungan antar Variabel & B & P \\
\hline Ada hubungan antara mindfulness dengan perilaku peran sakit & 0.51 & 0.00 \\
\hline
\end{tabular}

Tabel diatas menunjukkan ada hubungan dengan arah positif antara mindfulness dan perilaku peran sakit. Hasil diperoleh bahwa mindfulness memiliki hubungan yang positif dan signifikan dengan perilaku peran sakit $(\beta=0.51, \mathrm{p}<$ 0.01 ), artinya $\mathrm{H}_{1}$ diterima. Hal ini berarti bahwa mindfulness yang tinggi menyebabkan perilaku peran sakit yang tinggi, dan sebaliknya mindfulness yang rendah menyebabkan perilaku peran sakit yang rendah. 


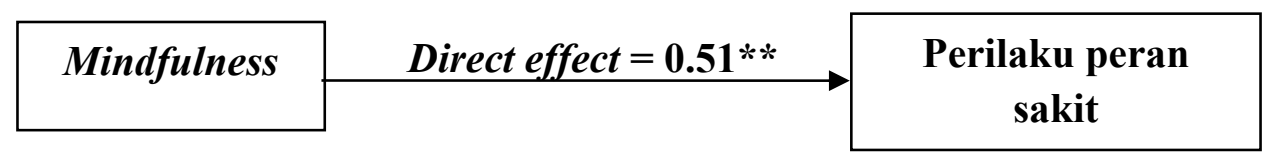

Keterangan : ** $\mathrm{p}>0.05$

\section{Pembahasan}

Hasil penelitian menunjukkan bahwa mindfulness memiliki hubungan yang positif dan signifikan dengan perilaku peran sakit. Penderita pasca stroke yang selalu berusaha untuk menerima keadaan yang terjadi pada dirinya saat ini tanpa berusaha menghakimi dapat membuat mereka tidak menyalahkan keadaan yang sedang terjadi sehingga mereka akan melakukan tindakan penyembuhan dengan melakukan kunjungan ke dokter atau tidak melakukan sesuatu yang merugikan bagi proses penyembuhannya.

Mindfulness dapat mengarahkan individu untuk dapat memberikan kontrol yang lebih besar dalam kehidupannya sehingga mereka dapat melakukan hal-hal yang lebih bermanfaat (Shapiro, Walsh, \& Britton, 2003). Adanya keterbukaan, penerimaan terhadap pengalaman yang terjadi saat ini, ditambah dengan pengamatan diri yang tidak reaktif bermanfaat dalam pengaturan diri yang konsisten dengan orang yang lebih luas (Ryan, Kuhl, \& Deci, 1997). Mindfulness mampu memperbaiki kondisi psikologis dan kualitas hidup individu dengan penyakit kronis menjadi lebih baik (Lengacher et al., 2009).

Secara khusus mindfulness mengajarkan seseorang untuk memperhatikan dan mengakui pengalaman yang terjadi, tanpa harus bereaksi. Kemampuan untuk hanya mengamati dan merasakan secara akurat perasaan, emosi, dan sensasi fisik tanpa harus mengubahnya, atau bertindak terhadapnya dapat berperan penting dalam memecahkan pola perilaku kebiasaan yang dapat membahayakan kesehatan seseorang (Greeson, 2009). Setidaknya penelitian telah menunjukkan bahwa terjadinya perubahan perilaku seperti berkurangnya penggunaan zat, rokok dan kemampuan untuk melakukan hal-hal yang bermanfaat dikarenakan dalam mindfulness terdapat adanya penerimaan bukan penghindaran dari pikiran-pikiran yang tidak diinginkan (Bowen, Witkiewitz, Dillworth, \& Marlatt, 2007; Davis, Fleming, Bonus, \& Baker, 2007).

Penelitian menunjukkan bahwa mindfulnes yang dilatih dapat mengatasi tekanan, masalah dalam kehidupan seharihari atau stres yang luar biasa. Selain itu, mindfulness yang terkontrol juga bermanfaat bagi kesehatan pasien dengan berbagai gangguan kronis (Grossman, Niemann, Schmidt, \& Walach, 2004). Melalui mindfulness, pasien dapat lebih menyadari emosinya, meningkatkan kesadaran diri dan memberikan ketenangan sehingga pasien dapat berpikir positif dan lebih mudah untuk mencapai penerimaan (Davis et al., 2007). Pasien yang sudah menerima dengan ikhlas, memiliki kondisi psikologis yang lebih fleksibel sehingga mampu fokus pada masa sekarang untuk melakukan proses perawatan, serta keterbukaannya terhadap pengalaman yang dialaminya sangat tinggi sehingga bersedia menerima atau mengalami peristiwa yang tidak diinginkan (Hayes, Luoma, Bond, Masuda, \& Lillis, 2006).

\section{KESIMPULAN}

Berdasarkan hasil penelitian dapat dikatakan bahwa terdapat adanya hubungan positif yang cukup signifikan antara mindfulness dengan perilaku peran sakit pada pasien stroke. Hal ini menunjukkan jika semakin tinggi tingkat mindfulness yang dimiliki pasien stroke, 
maka semakin tinggi pula perilaku peran sakit pasien stroke dalam melakukan proses penyembuhan. Sebaliknya, semakin rendah mindfulness yang dimiliki pasien stroke, maka semakin rendah pula perilaku peran sakit pasien stroke dalam melakukan proses penyembuhan.

Kondisi mindfulness secara pasti mampu mengarahkan individu dalam melakukan hal-hal yang positif dalam kehidupan sehari-hari. Oleh karena itu, sebaiknya individu berlatih untuk mencapai kondisi mindfulness untuk manfaat yang lebih baik. Selain itu, perlu juga dilakukan penelitian-penelitian lebih lanjut terkait variabel-variabel lain yang memiliki kemungkinan untuk berperan dalam perilaku peran sakit seperti perceived stres, self acceptance dan religiusitas. Penambahan subjek dari beberapa wilayah juga bisa jadi pertimbangan agar lebih banyak menggambarkan perilaku peran sakit pada beragam budaya.

\section{REFERENSI}

1. Barclay, D. A. (2012). Impact of "sick" and "recovery" roles on brain injury rehabilitation outcomes. Rehabilitation Research and Practice, 20(12), $1-10$. https://doi.org/10.1155/2012/725078

2. Bogousslavsky, J. (2003). William Feinberg lecture 2002: Emotions, mood, and behavior after stroke. The American Heart Association, 34(4), 1046-1050.

https://doi.org/10.1161/01.STR.00000 61887.3S3505.B9

3. Bowen, S., Witkiewitz, K., Dillworth, T. M., \& Marlatt, G. A. (2007). The role of thought suppression in the relationship between mindfulness meditation and alcohol use. Addictive Behaviors, 32(10), 2324-2328. https://doi.org/10.1016/j.addbeh.2007. 01.025

4. Chriki, L. S., Bullain, S. S., \& Stren,
T. A. (2006). The recognition and management of psychological reactions to stroke: A case discussion. Journal of Clinical Psychiatry, 8(4), 234-240.

5. Davis, J. M., Fleming, M. F., Bonus, K. A., \& Baker, T. B. (2007). A pilot study on mindfulness based stress reduction for smokers. BMC Complementary and Alternative Medicine, 7(2), 1-7. https://doi.org/10.1186/1472-6882-7-2

6. Eriksson, H., Milberg, A., Hjelm, K., \& Friedrichsen, M. (2016). End of life care for patients dying of stroke: A comparative registry study of stroke and cancer. PLoS ONE, 11(2), 1-10. https://doi.org/10.1371/journal.pone.0 147694

7. Garland, E. L. (2007). The meaning of mindfulness: A second-order cybernetics of stress, metacognition, and coping. Complementary Health Practice Review, 12(1), 15-30. https://doi.org/10.1177/153321010730 1740

8. Greeson, J. M. (2009). Mindfulness research update: 2008.

Complementary Health Practice Review, 14(1), 10-18. https://doi.org/10.1177/153321010832 9862

9. Grossman, P., Niemann, L., Schmidt, S., \& Walach, H. (2004). Mindfulness-based stress reduction and health benefits: A meta-analysis. Journal of Psychosomatic Research, $57(1)$, $35-43$. https://doi.org/10.1016/S00223999(03)00573-7

10. Hayes, S. C., Luoma, J. B., Bond, F. W., Masuda, A., \& Lillis, J. (2006). Acceptance and commitment therapy: Model, processes and outcomes. Behaviour Research and Therapy, 44(1), 1-25. https://doi.org/10.1016/j.brat.2005.06. 006

11. Lengacher, C. A., Johnson-Mallard, V., Post-White, J., Moscoco, M. S., 
Jacobsen, P. B., Klein, T. W., ... Kip, K. E. (2009). Randomized controlled trial of mindfulness-based stress reduction (MBSR) for survivors of breast cancer. Psycho-Oncology, 18(12), 1261-1272. https://doi.org/10.1002/pon.1529

12. Leung, D. P. K., \& Liu, K. P. Y. (2011). Review of self-awareness and its clinical application in stroke rehabilitation. International Journal of Rehabilitation Research, 34(3), 187195.

https://doi.org/10.1097/MRR.0b013e3 283487f31

13. Ludwig, D. S., \& Kabat-Zinn, J. (2008). Mindfulness in medicine. Jama, 300(11), 1350-1352. https://doi.org/10.1001/jama.300.11.1 350

14. Maine, M., McGilley, B. H., \& Bunnell, D. W. (2010). Treatment of Eating Disorders: Bridging The Research-Practice Gap. London: Academic Press.

15. Mant, J., Winner, S., Roche, J., \& Wade, D. T. (2005). Family support for stroke: One year follow up of a randomised controlled trial. Journal of Neurology, Neurosurgery \& Psychiatry, 76(7), 1006-1008. https://doi.org/10.1136/jnnp.2004.048 991

16. National-Stroke-Association. (2012). Stroke Recovery. Retrieved August 3, 2016, from http://www.stroke.org/wecan-help/survivors/stroke-recovery

17. Ruff, K. M., \& Mackenzie, E. R. (2009). The role of mindfulness in healthcare reform: A policy paper. Explore: The Journal of Science and Healing, 5(6), 313-323. https://doi.org/10.1016/j.explore.2009. 10.002

18. Ryan, R. M., Kuhl, J., \& Deci, E. L. (1997). Nature and autonomy: An organizational view of social and neurobiological aspects of selfregulation in behavior and development. Development and
Psychopathology, 9(4), 701-728. https://doi.org/10.1017/S09545794970 01405

19. Sarah, G., \& Clark, L. (2011). Psychological care after stroke: Improving stroke services for people with cognitive and mood disorders. NHS Improvement - Stroke, 1-28.

20. Shapiro, S. L., \& Carlson, L. E. (2009). The Art and Science of Mindfulness: Integrating Mindfulness Into Psychology and the Helping Professions. Washington, DC: American Psychological Association.

21. Shapiro, S. L., Walsh, R., \& Britton, W. B. (2003). An analysis of recent meditation research and suggestions. Journal for Meditation Researches, 3(2), 69-90.

22. Winarsunu, T. (2006). Statistik dalam Ilmu Penelitian Psikologi dan Pendidikan. Malang: UMM Press. 